\title{
China and Europe networks in Health. An empirical analysis on co- publications
}

\author{
Lauretta Rubini* \\ Department of Economics and Management, University of Ferrara \\ Via Voltapaletto, 11 - Ferrara, Italy \\ E-mail: lauretta.rubini@unife.it
}

\section{Chiara Pollio}

Department of Economics and Management, University of Ferrara

Via Voltapaletto, 11 - Ferrara, Italy

E-mail: chiara.pollio@unife.it

\begin{abstract}
China formally opened its economy in 1979, with the launch of the open door policy. The center of this process has been knowledge acquisition, strongly pushed by the government mainly through incentives to collaborations with foreign firms and institutions. However in more recent years problems of long-term sustainability have started to be raised, especially on the necessity to couple the economic growth with an increase in the population well-being. Health is a pivotal sector in terms of impact on life quality of the population, as testified by the plethora of studies aimed at measuring the health-related quality of life. For this reason, to deepen the knowledge of the factors and the dynamics regulating enhancements in this field becomes particularly relevant. Progress in health directly derives from progresses made in scientific research, and publications are a widely recognized tool for the divulgation of knowledge in this field. In this framework, this paper analyzes the evolution of international cooperation of Chinese institutions in health-related scientific fields, measured in terms of copublications. Changes in China's position in the international scientific literature will be traced, focusing then on the current structure of co-authorships with the first five EU countries in terms of GDP and highlighting differences in the weight, the structure and the degree of complexity of the relation networks.
\end{abstract}

Keywords: co-publications, health, China, science.

\section{Biographical notes:}

Lauretta Rubini is a researcher at the Department of Economics and Management of the University of Ferrara. She has a long teaching activity in Applied Economics, Industrial Organization and Industrial Policy and lectures in several Masters programs. She got a PhD in Business at the University of Birmingham (UK) and she has participated in several research projects both at national and international level. She is also a senior researcher at c.MET05, a Inter-university Center on Applied Economic Studies to Industrial Policies, Local Development and Internationalization. Among her research interests: health industry, industrial policies, SMEs and firms' agglomerations dynamics, high-tech networking, innovation processes, China's industrial development.

Chiara Pollio is a fellow researcher in Industrial Economics and Policy at the Department of Economics and Business of the University of Ferrara (Italy). She is also researcher of c.MET05, a Inter-university Center on Applied Economic Studies to Industrial Policies, Local Development and Internationalization.

\footnotetext{
* Corresponding author
} 
Her main research fields cover: the development of East Asian economies (China and Southeast Asia), the automotive industry, selective policies, scientific collaborations and technology transfer, research networks and research quality. 


\section{Introduction}

China formally opened its economy in 1979, when Deng Xiaoping launched the socalled open door policy, i.e. a government policy favoring the modernization of the Chinese socialist economy by opening up to the global capitalistic market (Di Tommaso et al., 2013; Elleman, 2015). No doubts that this represents a milestone in the modern history of the country, identifying one of the most important changes in the Chinese attitude towards the external world.

The center of China's modern evolution has been knowledge acquisition, strongly pushed by the government by means of incentives to collaborations with foreign firms and institutions, at all levels. In a first phase, this has mainly been done by encouraging joint ventures and business collaborations. Afterwards other measures have been introduced to stimulate also scientific relations with academics localized in other nations, or to encourage the growth in the flow of Chinese students graduating abroad ${ }^{1}$.

On the one hand, this process of knowledge acquisition and technological upgrading has fed the impressive economic growth of the country, but on the other, some studies underline problems of long-term sustainability, especially related to the necessity of improving the quality of life and increasing the social well-being (Di Tommaso et al., 2013; Li, 2012; Knight and Gunatilaka, 2012, and many more). A key aspect affecting such a well-being is the quality of health provided to the population (Di Tommaso and Schweitzer, 2012), that in China still seems to be lagging behind (Eggleston et al., 2008; Liang and Guo, 2015; Blumenthal and Hsiao, 2015 to cite some). Already in 2005, a WHO report signaled that improvements in health were not keeping the pace with the economic growth of the country (WHO, 2005).

The 2011-2015 5-year plan aimed at reaching an "inclusive growth", i.e. to ensure that economic growth benefits a wider part of the population. In order to reach such an ambitious target, the Chinese government has put health at the center of the public action, with investments to improve the provision of healthcare services but also to favor enhancements in health-related industrial fields. Both objectives require a solid base of scientific research, which is essential to improve the quality of life of citizens and to strengthen the competitiveness of the domestic health-related manufacturing sectors. More and more often, such scientific research is carried out by means of trans-national cooperation networks. This aspect, coupled with the strong propensity shown by the Chinese governments to acquire competences through collaborations with external partners, induces us to believe that the study of the international cooperation of China in health sciences may represent an important element in the overall picture of the national strategy for health improvement and promotion.

\footnotetext{
${ }^{1}$ In 2014 they amounted to almost 500.000 postgraduates (with an $11 \%$ yearly increase), about $80 \%$ of which returning to their home country (China National Statistics).
} 
In this framework, in this paper we analyze the international cooperation of Chinese actors in health-related scientific fields, measured in terms of co-publications. Progress in health directly derives from the progresses made in the scientific research, and publications are one of the most widely recognized tools for the divulgation of knowledge in this field. The following section briefly reviews the literature on international cooperation in science. Section 3 analyzes the evolution over time of the international cooperation in science of Chinese contributors, with a focus on health-related subjects. It then studies the current co-publication networks with the first 5 EU countries in terms of GDP, trying in particular to introduce the role that complexity plays in shaping such networks. Section 4 presents some final remarks and draws the lines for future research.

\section{International cooperation in science. A review of the literature}

Even if cooperation in science has grown noticeably starting from the 1950s, this phenomenon has much more ancient roots. In their detailed analysis on the origins and evolution of collaboration in research, Beaver and Rosen (1978, 1979a and 1979b) underline that such cooperation dates back to the $17^{\text {th }}$ century (the first co-authored paper was published in 1665). In the period 1800-1830 the collaboration was almost exclusively carried out by French chemists, then it started to grow worldwide, at a slow pace until the First World War and more rapidly afterwards. In particular, after the Second World War, there has been an increase not only in the number of research networks, but also in that of partners involved in each of them. In particular, there has been a shift from small teams made up of 2-3 institutions to so-called "giant collaborations", which according to the authors are currently the rule (Beaver and Rosen, 1978, 1979a and 1979b; Beaver, 2001).

Beaver and Rosen claim that collaboration among scientists is the consequence of a progressive and graduated professionalization ${ }^{2}$ of science, i.e. "a process which organizes a group of individuals along a set of attributes ... (that) defines the rules, rights, and rites of access to the group, what holds the members of the group together, and what sets them apart from other individuals in the larger society. Furthermore, professionalization structures the obligations and benefits of the group's members while defining their relationships with outsiders" (Beaver and Rosen, 1978, pp. 66-67). In other words, collaboration among scientists started soon after the establishment of scientific societies $^{3}$, which enjoyed increasing state support and autonomy. Within this process, collaboration was mainly a tool used by the scientific elite (or by those who aspired to it) to be acknowledged by the professional community. Collaboration implied a multiplication of the mobility occasions and a great increase in the visibility of all the

\footnotetext{
${ }^{2}$ What Schott (1998) also calls institutionalization.

${ }^{3}$ The French Academy of Science was founded in 1666, the British Royal Society in 1660 and the German Leopoldina Academy of Researchers in 1652 (Ornstein, 1963).
} 
scientists involved. The authors also underline that this has been, since the beginning, a sort of self-reinforcing procedure: "the more often collaboration links researchers together, and the longer such linkages can be extended, the more integrated in the community and the more mutually dependent are its members" (Beaver and Rosen, 1978, p. 80). Consequently, this process of mutual acknowledgement and professional enhancement has strongly contributed to accelerate the advance of science, because it has allowed and allows to exchange and combine ideas, competences and resources and, ultimately, to favor technological progress (Beaver and Rosen, 1978; Hennenmann and Liefner, 2015; Gao et al., 2011; Fox and Faver, 1984).

Within the dynamics regulating the overall phenomenon of cooperation in science, in more recent years there has been a substantial growth of networks of institutions belonging to different countries (Guan and Ma, 2004; Moed, 2005; Kyvik and Larsen, 1994; Melin and Persson, 1996; Beaver, 2001; De Lange and Glänzel, 1997). Internationalization in science is a process that dates back to the $19^{\text {th }}$ century, enrooted in the complementarity of competences, but the trend has grown noticeably in relatively recent years, becoming a "globalization of science" (Gómez et al., 1999; Zitt and Bassecoulard, 2004; Rubini, 2010). Nagpaul (2003) quotes that between the early 1980s and the beginning of the 1990s, the number of publications in the 45 most scientifically advanced countries increased by $2.6 \%$ per year, while the number of trans-national cooperation links grew in the same period at an annual rate of $11.1 \%$. Zitt and Bassecoulard (2004) report instead that the rate of internationally co-authored papers has almost doubled from 1990 to 2000, with about $7 \%$ of annual growth.

This increase in cooperation in science has several explanations. First of all, it is related to the rising complexity in innovative dynamics that makes it inevitable to acquire knowledge from external and complementary sources, reducing the degree of uncertainty and the time and efforts needed to gain the necessary competences (Scherngell and Barber, 2009; He, 2009). International linkages are needed for a country in order to take part in the world scientific scenario: "institutions that do not form international collaborations risk progressive disenfranchisement and countries that do not nurture their talent will lose it entirely" (Adams, 2013, p. 557).

By means of trans-national linkages, scientists have the possibility to access scientific facilities that may not be available locally, or that require enormous investment efforts. They may also benefit from cross-nurturing processes enriching their skills (Francisco, 2015). Furthermore, collaborating with other countries can facilitate the access to research funds devoted to improve the relations with specific countries (in many cases developing countries), as a way to favor the flow of knowledge and expertise towards these nations (Oldham, 2005). Finally yet importantly, internationally coauthored papers tend to be easier to place on relevant journals, usually receive more attention from peers and therefore tend to be more cited (Adams and Loach, 2015; Royle et al., 2007; Adams, 2013). 
When looking for a way to measure science, its evolution and progress, the literature considers publications an important indicator (van Raan, 2004). They are the main tool used to diffuse knowledge and to enable the process of scientific progress (Braun, 2004). Consequently, despite some limitations (Jonkers, 2009), co-authorships can be considered "one of the most tangible and well documented forms of scientific collaboration" (Glänzel and Schubert, 2004, p. 257) and are used in numerous studies analyzing national and international research networks (Jonkers, 2009; Luukonen et al., 1993; Adams and Loach, 2015; Endenich and Trapp, 2015, to cite some). Such links tend not only to increase with time, but also to define stable and persistent networks among researchers and countries (Acedo et al., 2006; Uddin et al., 2012).

\section{The international evolution of Chinese scientific collaborations in health: an empirical analysis}

\subsection{China in the international scientific scenario}

The opening process which has characterized China since the end of the 1970s has also affected the national scientific elite, even if at a different pace. Until the mid-2000s, in fact, Chinese scientists were strongly "inward oriented" and scarcely disposed to publish in international, foreign-language journals (He, 2009). This is confirmed analyzing the SCOPUS database ${ }^{4}$, which shows that the Chinese presence has been marginal until the mid-2000s. Due to political reasons, it was very rare for a Chinese scientist to publish abroad (He, 2009). This trend completely changed from 2004, with internationally co-authored papers starting to grow very rapidly, and amounting to $17 \%$ of the total in 2014 (fig. 1), against an average annual economic growth of about $10 \%$ (Andersson et al., 2014).

\section{[FIGURE 1 HERE]}

Since 2005, China ranks second for number of publications in the SCOPUS database (tab. 1). Several reasons may explain this steady growth. The first to be mentioned is the so-called "go abroad" strategy (Di Tommaso et al., 2013). In recent years, the government has started to favor the presence of Chinese actors on foreign markets, both as a way to acquire new market shares and to affirm the growing weight of the country at the world level. Science undoubtedly represents a key aspect in this process of international affirmation of the country, and a relatively fast way to increase the presence of Chinese scientists in international publications is the establishment of trans-

\footnotetext{
${ }^{4}$ It is the largest abstract and citation database of peer-reviewed literature (Elsevier, 2014), with almost 35,000 journals and 3 million articles.
} 
national research networks. According to He (2009), the international collaboration is particularly needed for China in order to take full advantage of foreign technology, knowledge and equipment and to gradually reduce the gap with the so-called advanced countries. Knowledge acquisition in fact is recognized as fundamental for long-term economic growth (Gao et al., 2011). There are several studies showing a steady rise in international co-authorship of the country at world level, with no apparent sign of saturation (Glänzel and Schubert, 2004; Moed et al., 2004; Zhou and Bornmann, 2015; Guo et al., 2000).

\section{[TABLE 1 HERE]}

A possible explanation for this growth could be the overall increase in the political and economic weight of the country at international level, which has been proved to affect per se the number of international co-publications (Glänzel and Schubert, 2004). But this increase is also the consequence of specific actions taken by the government, aimed at strengthening the net of international scientific relations.

First of all, in 1986 - shortly after the launch of the open door policy - the government established the National Natural Science Foundation of China (NSFC). This is a publicly funded institution having the aim of "supporting basic research, fostering talented researchers, developing international cooperation and promoting socio-economic development" . This has represented a milestone in the internationalization of Chinese research: especially in recent years, the Foundation has encouraged international cooperation at all levels (He, 2009), with a budget specifically devoted to this aim passing from 3 million Yuan in 1987 to 82 million at present. Furthermore, the NSFC has signed to this purpose 70 cooperative agreements with partners in 35 countries and regions, boosting the role of China in the international scientific scenario.

The government has also strongly encouraged Chinese students to enroll in foreign universities, acquiring new knowledge to be used once back in their home country but also establishing relations with foreign scholars. This has been coupled with the decision taken in recent years by the government to strongly encourage overseas Chinese scholars working abroad to return to their home country (Zhou and Leydersdorff, 2006). After their repatriation, these academics have continued to work with their foreign colleagues thanks to the previously established connections, contributing to increase very rapidly the number of international co-authorships.

The network of relations between China and foreign countries is also fed by the Chinese scientists continuing to live abroad, who also tend to act as connectors between their current scientific community and that in their home country (Wang et al., 2013).

\subsection{Chinese role in scientific publications in the health fields}

\footnotetext{
${ }^{5}$ NSFC website: www.nsfc.gov.cn
} 
In the last few years there has been a growing interest towards the structure and features of knowledge production networks in China. Several contributors concentrated their attention on the study of inter-regional relations (Liang and Zhu, 2002; Wang et al., 2005; Ma et al., 2014), others focused on China's international collaborations (see, among others, He, 2009; Gao et al., 2011) or studied specific sub-sectors in depth (Tang, 2013; Jonkers, 2009). However, the existing literature still seems to lack to analyze international collaborations specifically referred to the health sector as a whole.

Given the already mentioned centrality of health for the economic and social wellbeing of the country, we believe that focusing on co-publications in this field might provide useful insights on the nature and intensity of Chinese scientific relations with the rest of the world. This study might also represent a first step to understand the factors affecting the quality of co-authored research in China in these sectors, which in turn might be useful to take into consideration while planning the policies to support scientific enhancement.

In this study we focus on Chinese publications in the nine SCOPUS sub-fields that are related to health studies: 1. Biochemistry, Genetics and Molecular Biology; 2. Chemistry; 3. Dentistry; 4. Health Professions; 5. Immunology and Microbiology; 6. Medicine; 7. Neuroscience; 8. Nursing 9. Pharmacology, Toxicology and Pharmaceuticals.

First of all, we refer to trend analysis (see e.g. Uddin et al., 2012) to study the evolution over time of the studied phenomenon. As for total publications of China, the number for this field has increased exponentially since 2001 (fig. 2). It is growing even faster than the global publications in the field, as it is testified by the huge increase since the same years of its weight on world publications.

\section{[FIGURE 2 HERE]}

However, this growth does not seem to suggest that the country's scientific production is specializing in this area. This is shown by the trend of the activity index (AI) (Zhou and Glänzel, 2010), which is used to identify the degree of specialization of a country in certain scientific fields. The AI is calculated as follows:

$$
A I=\frac{\text { world share of country } X \text { in publications in a given field }}{\text { share of country } X \text { in world total publications }}
$$

or, analogously

$$
A I=\frac{\text { share of the given field in the publications of country } X}{\text { share of the given field in world total publications }}
$$


Figure 3 shows the AI trend for China from 1980 to 2015. While in the first years of 1980s the country's level of specialization in health-related subjects was close to the world average, it has then heavily decreased until the first years of 1990s. Despite a subsequent recovery, according to the last data China still lags behind when compared with the first ten countries in terms of number of publications. Only Germany, France and Italy register lower degrees of specialization. This is confirmed by Jonkers (2009), according to whom China is still relatively more concentrated than the world average on other sectors, such as physics, coherently with what Glänzel (2001) finds out for former socialist countries. A possible explanation for this relatively lower interest of Chinese scientific environment towards health-related publications might be the fact that the NSFC opened a department specifically devoted to the promotion of health science only in 2010 .

\section{[FIGURE 3 HERE]}

In the same years in which Chinese publications in health in international journals started to grow (fig. 2), also the internationally co-authored publications boosted (fig. 4). However, while absolute numbers exponentially grew only from 2000s, the opening of the country's scientific community to international collaborations in health seems to have begun far before, in correspondence with the economic opening of China in the first years of 1980s. In fact, up to the beginning of 2000s, despite the still marginal weight of internationally co-authored publications, China had already started to enlarge the width of its international scientific network, constantly increasing the number of involved countries. This trend has continued afterwards, but coupled with a remarkable growth in the number of internationally co-authored papers.

\section{[FIGURE 4 HERE]}

\subsection{The current geography of Chinese scientific collaborations with Europe in health}

Most of the literature on scientific cooperation, both in health sciences and in other fields, has so far focused on the analysis of co-authorship or co-institutional networks (Owen-Smith et al., 2002; Morel et al., 2009; Melin and Persson, 1996 among many others). These studies usually stress either networks organizational features and properties (Powell et al., 2005; Abbasi et al., 2012; Uddin et al., 2013) or their temporal trends (Abbasi et al., 2011; Uddin et al., 2012) and mostly use the analytical and empirical tools of social network analysis (Otte and Rousseau, 2002).

The perspective of this work detaches from network analysis and concentrates on China's role and behavior in the collaborations related to health research, focusing on its relation with Europe. On one side, we want to assess the scope and strength of China and European countries collaborations in terms of number of publications, number of actors 
and number of countries involved. On the other, we want to evaluate whether there is a qualitative distinction among China's collaborations with different EU countries, addressing the theme of how much complex such relations are. We do so by using an original dataset, that we built and controlled by hand starting from the data on copublications extracted from SCOPUS. Given the vastness of information to be checked, we limited the analysis to the co-publications between China and the first five EU countries in terms of GDP (United Kingdom, Germany, France, Italy and Spain) in a single year. In particular, we have collected information about all the published works in 2014 in the field of health sciences, as defined above, that were co-written by at least one author with China ${ }^{6}$ as affiliation country and one author based in one of the five selected EU countries. After cleaning and double-checks, the final dataset resulted in 6,128 publications and 39,399 affiliations. Analyzing each authors' affiliations we have identified, for every publication, the countries and the type of institutions involved in the collaboration, divided in: university, hospital, company, association/foundation, public institution, university hospital. To the best of our knowledge, this represents the first database on co-publications in health fields between China and Europe that goes in such details in describing the geographical origins and the type of affiliations of the single partners in each publications.

Given the different importance of the five selected countries in the international scientific scenario, as it is reflected by SCOPUS data (see tab. 1), it is reasonable to assume that also the relations they have with China in terms of co-publications differ. A first confirmation is given by the position of each selected country as a partner in health publications with China (fig 5). The five European countries are since the beginning among the top 20 collaborating partners, and their reciprocal positions appear to be stable over time. United Kingdom always remains one of the most important partners of China in this field, often overtaken only by the US. Germany and France rank among the top 10 China's partners, although they show a less stable trend across time. However, the most unstable position is that of Italy, whose variation goes from the ninth (in 1990) to the $14^{\text {th }}$ (both in 1985 and in 2005) position, while Spain's trajectory - lagging between the $20^{\text {th }}$ and the $16^{\text {th }}$ - appears to be steadier.

\section{[FIGURE 5 HERE]}

Another way to investigate the strength of China's relation with each of these countries is to try to quantify the intensity of the co-publication activity. To do so, we have used the Salton's measure, which is a commonly adopted indicator of co-authorship density. The index is calculated as the number of joint publications between two countries divided by the square root of the product of the number of total publication outputs of the

\footnotetext{
${ }^{6}$ Since Hong Kong and Macao returned to mainland China in 1997 and 1999 respectively, we have decided to include them in the database.
} 
two countries (Zhou and Glänzel, 2010; Barth et al. 2014; He, 2009). We have applied the index to all the co-publications between China and the selected EU countries in 2000 and 2014 (tab. 2).

\section{[TABLE 2 HERE]}

For all the considered countries the collaboration with China has increased over time and data confirm what already observed through the rankings. UK is the preferred collaborator for Chinese scientists, followed by Germany and France and, at a greater distance, by Italy and Spain, and this ranking is stable over time.

Historical and cultural factors could be at the basis of the different importance as publishing partners of the selected countries. For example, the prominence of UK has been explained by the existence of "neo-colonial ties in science" (Nagtegaal and De Bruin, 1994). However, a strategic role in shaping this picture might, once again, have been played by the central government (Jonkers, 2009). As already mentioned, the NSFC, in fact, has provided institutional support to international relations by signing agreements with a number of foreign-based institutions, among which those in UK prevail. The specific agreements facilitating international collaborations on health-related issues signed with the selected countries are illustrated in table 3.

\section{[TABLE 3 HERE]}

The case of Germany also deserves further specifications. The scientific collaboration between this country and China has been fostered by the establishment in 2000 of the Sino-German center for research promotion, through which the two countries jointly invest about 20 million Yuan per year to fund cooperation between their scientists ${ }^{7}$.

Other possible explanations of the different degree of intensity in co-publications with the selected countries could be the scientific mobility flows among the countries, the weight of the Chinese scientific community within a partner country or the language, given that SCOPUS publications are mainly in English (Jonkers, 2009).

When zooming on the co-publications between China and the 5 selected EU countries in health-related issues for the year 2014, the picture is confirmed. The preferred co-author country remains United Kingdom, followed by Germany, France, Italy and Spain. Table 4 and figures A1-A4 in the Appendix summarize and illustrate the different structure of the co-authorship research networks with China.

\section{[TABLE 4 HERE]}

\footnotetext{
${ }^{7}$ NSFC website.
} 
This first glimpse seems to reveal strong differences not only in the total number, but also in the structure of the collaboration with the five selected countries. While, in fact, for UK, Germany and France about $50 \%$ of co-publications are bilateral, for Italy and Spain the relation seems to be far less "exclusive". Furthermore, there is an inverse relationship between the number of co-publications, on one side, and the average number of partners and regions/countries ${ }^{8}$ per publication, on the other. While for United Kingdom the network is smaller and more exclusive, in the case of Italy and Spain the average number of partners per publication is noticeably higher, as well as the average number of regions/countries per publication.

So far, we have considered two dimensions to evaluate the degree of complexity of the existing networks: the number of partners in the co-publications and the vastness of the network, in terms of number of regions involved. However, there is at least another aspect that contributes to determine the complexity of the co-authorship networks, that is the variety of actors, in terms of types of institutions they belong to: the less similar the institutions involved, the more complex the shape of the network that carries out the collaboration. Table 5 indicates the participation of the six types of institutions in the scientific network with China, divided by country. We can observe a clear difference between UK and Germany, on one side, and the other countries on the other. Universities prevail in United Kingdom and to a lower extent in Germany: in both cases they represent more than a half of the institutions taking part in the scientific networks with Chinese partners. France, Spain and Italy show a more fragmented picture, with a relatively larger involvement of public institutions (for France) or hospitals (for Italy), or a mix of several types (Spain). Instead, China shows a stronger involvement of academic institutions in these collaborations, that take by far the major role, either alone or in the form of university hospitals.

\section{[TABLE 5 HERE]}

To consider the three dimensions of complexity in isolation provides some information, but does not allow getting a complete picture. In other words, the analysis might be more informative by finding a way to consider the three aspects simultaneously. In order to do so, we have built a composite complexity index. To generate it, we have

\footnotetext{
${ }^{8}$ To build up the database we collected information for the collaboration in the publications for each country. In a second stage, we aggregated the data by regions of countries, following the UN Geographical region and composition of each region list (available at http://unstats.un.org/unsd/methods/m49/m49regin.htm). We left single-country data for China, the 5 selected EU countries and the US, given the amount of publications including American co-authors. This led to aggregating the countries in 20 groups, resulting as follows: Africa, Central Asia, Canada, China, Germany, Eastern Asia (China excluded), Eastern Europe, Spain, France, Italy, Latin America, Northern Europe (United Kingdom excluded), Oceania, Southern Asia, South-eastern Asia, Southern Europe (Italy and Spain excluded), UK - United Kingdom, USA, Western Asia, Western Europe (France and Germany excluded).
} 
created three variables: a) the number of partners involved in the publication (dimension), b) the number of regions of the world involved in the publication (vastness) and c) the number of types of institutions involved in the publication (variety).

In origin, these variables were very heterogeneous among each other, above all for their range of variability: "dimension" had a minimum of 2 and a maximum of 300 partners; "vastness" varied from 2 (only China and one of the considered European countries involved) to 20 (all the regions of the world involved); finally, "variety" ranged from 1 (only 1 type of partner) to 6 (all the types of partner). To allow for their combination in a composite index, the three variables were firstly standardized (to center them on the same mean value) and then normalized (to allow for variation between 0 and 1). Then, we used an additive formula to build the complexity index for each publication $C_{i}$ :

$$
C_{i}=\sum_{j=1}^{k} \omega_{i} z_{i j}, \quad i=[1 . n] \text { and } j=[1, k]
$$

Where $z_{i j}$ is the normalized and standardized value of the variable $j$ related to the publication $i$. Because we assigned to each variable equal weight $\omega_{j}=\frac{1}{k}$, the index results as the arithmetic mean of the standardized and normalized values of the variables. When $C_{i}=0$, the publication $i$ has minimum degree of complexity: that is, it only involves two partners (minimum dimension) from two regions of the world (minimum vastness) that belong to the same type of institution (minimum variety). When $C_{i}=1$, the publication $i$ has the maximum degree of complexity: it involves 300 partners (the maximum number of partners present in our population), from all the regions in the world (maximum vastness), belonging to all the types of institutions considered (maximum variety).

We divided the values of the obtained index in eleven classes. The class where $C_{i}=0$ is the one with the lowest complexity; on the other hand, since we do not have any publication for which $C_{i}=1$, we consider the class where $0.9<C_{i}<1$ as the one approximating the maximum degree of complexity. Results are presented in figure 6.

\section{[FIGURE 6 HERE]}

The comparison of the index for the co-publications of the five European countries with China reveals rather different trends, confirming the picture sketched in table 3 . All countries show a prevalence of co-publications in the second and third classes of complexity. However, while the weight of UK, Germany and France surpasses Italy and Spain in the first two classes (those with the minimum degree of complexity), the incidence of Italy and Spain becomes relatively higher in the last classes, i.e. those with the highest level of complexity. This aspect seems particularly relevant to us and worth to be further investigated in future research. 


\section{Final remarks and future research}

Knowledge exchange is a key tool for economic development and competitiveness. The Chinese government seems to be aware of the centrality of science for its social and economic growth and health plays a determinant role in allowing to reach a socially sustainable economic growth. Together with co-invented patents, a co-authored paper is the main type of outcome facilitating knowledge transfer across regions and nations (Gao et al., 2011). We believe that our paper contributes to the literature in the field of scientific collaborations between China and the rest of the world in the health sector in several ways, and gives some promising hints for further research.

First, to the best of our knowledge this is one of the first studies on the state of coauthorship activity between China and the EU in health-related subjects. Second, focusing on the 5 largest countries in terms of GDP, we have built up an original and comprehensive one-wave database that contains detailed information about countries of origin and types of institution involved in the whole number of co-published papers with China in the health fields. Third, while the literature on networks generally focuses on only one or two aspects of networks, we built a three-dimensional index of complexity that allowed us to observe at once the various sources of complexity (dimension, vastness and variety) that shape the relations between China and the five selected countries.

The first exploratory exercise we presented in this work highlights some interesting stylized facts on the complexity of such networks: first, we observed that the vastness, the variety and the dimension of networks seem to be larger for those countries that collaborate the least with China. In other words, the co-publishing activity between China, on one side, and UK, Germany and France, on the other, tends to be rich in terms of number of publications but simple and mainly bilateral, while larger degrees of complexity seem to characterize the collaboration with Italy and Spain. Further research is needed to understand the reasons behind such differences in terms of complexity among these networks.

This first exploratory study has also provided some preliminary information that can be the basis for further analysis on the factors affecting the quality of scientific collaboration in health-related fields. There are differences not only in the intensity but also in the complexity of the relations with each of the considered nations that could affect the quality of the scientific research and therefore the benefits that can derive to the health systems of the involved countries. On one side, it is reasonable to assume that complexity might have a negative impact on the quality of research due to increasing costs in managing the network (Messner, 1997; Olson, 1965 and others). On the other, thanks to more complex and richer networks of relations, the cross fertilization among scientists might increase, with positive effects on the results of the jointly carried out research (Hennenman and Liefner, 2015; Gao et al., 2011 and so forth). Which of the two impacts prevails will be at the center of our future studies, extending the analysis to consider a 
longer time span and investigating not only the factors affecting the quality of research but also the existence of differences across countries.

Given the social sensitiveness of healthcare research and services lately acknowledged by the Chinese governments, understanding to what extent the collaborations between China and the EU are able to generate knowledge spillovers and high quality research becomes a crucial issue. For the first, there is little doubt that scientific collaboration might determine knowledge spillovers that could allow (and are actually allowing) China to fill the technological gap with western industrialized countries. On the other side, there are rising concerns, for example in the US, about the possibility that China's improved research capabilities might endanger US technological leadership (Tang, 2013). While this might be true for technology intensive sectors, such as nanotechnology, telecommunications, etc., in the case of health, the mutual exchange of knowledge and competences might end in a win-win game, allowing all partners to improve their health systems and to ultimately increase the well-being of their population.

\section{References}

Abbasi, A., Chung, K.S.K. and Hossain, L. (2012) 'Egocentric analysis of co-authorship network structure, position and performance', Information Processing \& Management, Vol. 48, No. 4, pp. 671-679.

Abbasi, A., Hossain, L., Uddin, S. and Rasmussen, K.J. (2011) 'Evolutionary dynamics of scientific collaboration networks: multi-levels and cross-time analysis', Scientometrics, Vol. 89 No. 2, pp. 687-710.

Acedo, F. J., Barroso, C., Casanueva, C. and Galán, J.L. (2006) 'Co-authorship in management and organizational studies: An empirical and network analysis', Journal of Management Studies, Vol. 43, No. 5, pp. 957-983.

Adams, J. (2013) 'Collaborations: The fourth age of research', Nature, Vol. 497, No. 7451, pp. 557-560.

Adams, J. and Loach, T. (2015) 'Comment: A well-connected world', Nature, Vol. 527, No. 7577, pp. S58-S59.

Andresson, D.E., Gunessee, S., Mathiessen, C.W. and Find, S. (2014) 'The geography of Chinese Science', Enviroment and Planning A, Vol. 46, No. 12, pp. 2950-2971.

Barth, M., Haustein, S. and Scheidt, B. (2014) 'The life sciences in German-Chinese cooperation: an institutional-level co-publication analysis', Scientometrics, Vol. 98, No. 1, pp. 99-117.

Beaver, D. deB. and Rosen, R. (1978) 'Studies in scientific collaboration - Part I. The professional origins of scientific co-authorship', Scientometrics, Vol. 1, pp. 65-84.

Beaver, D. deB. and Rosen, R. (1979a) 'Studies in scientific collaboration - Part II. Scientific coauthorship, research productivity and visibility in the French scientific elite', Scientometrics, Vol. 1, No. 2, pp. 133-149.

Beaver, D. deB. and Rosen, R. (1979b) 'Studies in scientific collaboration - Part III. Professionalization and the natural history of modern scientific co-authorship', Scientometrics, Vol. 1, No. 3, pp. 231-245.

Beaver, D. deB. (2001) 'Reflections on scientific collaboration (and its study): past, present and future'. Scientometrics, Vol. 52, No. 2, pp. 365-377. 
Braun, T. (2004) 'Keeping the gates of science journals', in Moed, H.F., Glänzel, W. and Schmoch, U. (Eds.): Handbook of Quantitative Science and Technology Research, Kluwer Academic Publishers, Dordrecht, pp. 95-114.

Blumenthal, D. and Hsiao, W. (2015) 'Lessons from the East - China's rapidly evolving health care system', New England Journal of Medicine, Vol. 372, No. 14, pp. 1281-1285.

De Lange, C. and Glänzel, W. (1997) 'Modelling and measuring multilateral co-authorship in international scientific collaboration. Part I. Development of a new model using a series expansion approach', Scientometrics, Vol. 49, No. 3, pp. 593-604.

Di Tommaso M.R., Barbieri E. and Rubini L. (2013) Southern China. Industry, development and Industrial Policy, Routledge, New York.

Di Tommaso M.R. and Schweitzer S.O. (2005) Health Policy and High Tech Industrial Development. Learning from Innovation in the Health Industry, Edward Elgar Publisher, Cheltenham.

Eggleston, K., Ling, L., Qingyue, M., Lindelow, M. and Wagstaff, A. (2008) 'Health service delivery in China: a literature review', Health economics, Vol 17, No. 2, pp. 149-165.

Elleman, B.A. (2015) International competition in China 1899-1991: The rise, fall and restoration of the open door policy, Routledge, New York.

Elsevier (2014) Scopus content coverage guide, Elsevier.

Endenich, C. and Trapp, R. (2015) 'Cooperation for publication? An analysis of co-authorship patterns in leading accounting journals', European Accounting Review, pp. 1-21.

Francisco, J.S. (2015) 'International Scientific Collaborations: A Key to Scientific Success', Angewandte Chemie International Edition, Vol. 54, No. 50, pp. 14984-14985.

Fox, M.F. and Faver, C.A. (1984) 'Independence and cooperation in research: The motivations and costs of collaboration', The Journal of Higher Education, Vol. 55, No 3, pp. 347-359.

Gao, X., Guan, J. and Rousseau, R. (2011) 'Mapping collaborative knowledge production in China using patent co-inventorship', Scientometrics, Vol. 88, pp. 343-362.

Glänzel, W. (2001) National characteristics in international scientific co-authorship relations, Scientometrics, Vol. 51, No. 1, pp. 69-115.

Glänzel, W. and Schubert, A. (2004) 'Analysing scientific networks through co-authorship', in Moed, H.F., Glänzel, W. and Schmoch, U. (Eds.): Handbook of Quantitative Science and Technology Research, Kluwer Academic Publishers, Dordrecht, pp. 257-276.

Gómez, I., Fernández, M.T. and Sebastián, J. (1999) 'Analysis of the structure of international scientific cooperation networks through bibliometric indicators', Scientometrics, Vol. 44, No. 3, pp. 441-457.

Guan, J. and Ma, N. (2004) 'A comparative study of research performance in computer science', Scientometrics, Vol. 61, No. 3, pp. 339-359.

Guo J.J., Cui L., Zhang, H., Han D.Y. and Chen J. (2000) 'Bibliometrics study of international cooperation in science and technology', Journal of the China Society for Scientific and Information Science, Vol. 19, No. 6, pp. 659-662.

He T. (2009) 'International scientific collaboration of China with the G7 countries', Scientometrics, Vol. 80, No. 3, pp. 571-582.

Hennenmann, S. and Liefner, I. (2015) 'Global science collaboration', in Archibugi, D. and Filippetti, A. (Eds.): The handbook of global science, technology and innovation, John Wiley \& Sons Ltd., Oxford, pp. 343-363.

Jonkers, K. (2009) 'Emerging ties: Factors underlying China's co-publication patterns with Western European and North American research systems in three molecular life science subfields', Scientometrics, Vol. 80, No. 3, pp. 775-795.

Knight, J. and Gunatilaka, R. (2012) 'Aspirations, Adaptation and Subjective Well-being of Rural-Urban Migrants in China', in Clark, D.A. (Eds.): Adaptation, Poverty and ISO 690 Development, Palgrave Macmillan, London, pp. 91-110.

Kyvik, S. and Larsen, I.M. (1994) 'International contact and research performance', Scientometrics, Vol. 29, No. 1, pp. 161-172. 
Li, B. (2012) 'Social welfare and protection for economic growth and social stability. China's experience', in A changing China: emerging governance, economic and social trends, Civil Service College, Singapore, pp. 39-60.

Liang, L.M. and Zhu, L. (2002) 'Major factors affecting China's inter-regional research collaboration: Regional scientific productivity and geographical proximity', Scientometrics, Vol. 55, No. 2, pp. 287-316.

Liang, Y. and Guo, M. (2015) 'Utilization of health services and health-related quality of life research of rural-to-urban migrants in China: a cross-sectional analysis', Social Indicators Research, Vol. 120, No. 1, pp. 277-295.

Luukonen, T., Tijssen, R.J.W., Persson, O. and Sivertsen, G. (1993) 'The measurement of international scientific collaboration', Scientometrics, Vol. 28, No. 1, pp. 15-36.

Ma, H., Fang, C., Pang, B. and Li, G. (2014) 'The effect of geographical proximity on scientific cooperation among Chinese cities from 19990 to 2010', PLos ONE, Vol. 9, No. 11, available online at journals.plos.org/plosone/article?id=10.1371/journal.pone.0111705

Melin, G. and Persson, O. (1996) 'Studying research collaboration using co-authorships', Scientometrics, Vol. 36, No. 3, pp. 363-377.

Messner, D. (1997) The network society, London, Frank Cass.

Moed, H.F. (2005) Citation Analysis in Research Evaluation, Springer, Dordrecht.

Moed, H.F. Glänzel, W. and Schmoch, U. (Eds.) (2004) Handbook of Quantitative Science and Technology Research, Kluwer Academic Publishers, Dordrecht.

Morel, C.M., Serruya, S.J., Penna G.O. and Guimarães R. (2009) 'Co-authorship Network Analysis: A Powerful Tool for Strategic Planning of Research, Development and Capacity Building Programs on Neglected Diseases', PLoS Negl Trop Dis, Vol. 3, No. 8: e501.

Nagpaul, P.S. (2003) 'Exploring a pseudo-regression model of transnational cooperation in science', Scientometrics, Vol. 56, No. 3, pp. 403-416.

Nagtegaal., L.W., De Bruin, R.E. (1994) 'The French connection and other neo-colonial patterns in the global network of science', Research Evaluation, Vol. 4, pp. 119-127.

Oldham, G. (2005) 'International scientific collaboration: A quick guide', Policy Brief, SciDevNet, available at www.scidev.net.

Olson, M. (1965) The Logic of Collective Action: Public Goods and the Theory of Groups, Harvard, Harvard College.

Ornstein, M. (1963) Role of scientific societies in the Seventeenth century. Reprinted edition, Archon Books, Handen \& London.

Otte, E. and Rousseau, R. (2002) 'Social network analysis: a powerful strategy, also for the information sciences', Journal of Information Science, Vol. 28, No. 6, pp. 441-453.

Owen-Smith, J., Riccaboni, M., Pammolli, F. and Powell, W.W. (2002) 'A Comparison of U. S. and European University-Industry Relations in the Life Sciences', Management Science, Vol. 48, No 1, pp. 24-43.

Powell, W.W., White, D.R., Koput, K.W. and Owen-Smith, J. (2005) 'The Life Sciences Network Dynamics and Field Evolution: The Growth of Interorganizational Collaboration in the Life Sciences', American Journal of Sociology, Vol. 110, No. 4, pp. 1132-1205.

Royle, J., Coles, L., Williams, D. and Evans, P. (2007) 'Publishing in international journals. An examination of trends in Chinese co-authorship', Scientometrics, Vol. 71, No. 1, pp. 59-86.

Rubini, L. (2010) 'Transfer of knowledge in science-based research networks: a case study on human health genetics in Italy', International Journal of Healthcare Technology and Management, Vol. 11, No. 4, pp. 304-324.

Scherngell T. and Barber M.J. (2009) 'Spatial interaction modelling of cross-region R\& collaborations: Empirical evidence from the EU Framework Programmes', Papers in Regional Science, Vol. 88, No. 3, pp. 531-546.

Schott, T. (1998) 'Ties between center and periphery in the scientific world-system: Accumulation of rewards, dominance and self-reliance in the center', Journal of WorldSystem research, Vol. 4, No. 2, pp. 112-144. 
Tang, L. (2013) 'Does "birds of a feather flock together" matter - Evidence from a longitudinal study on US-China scientific collaboration', Journal of Informetrics, Vol. 7, pp. 330-344.

Uddin, S., Hossain, L., Abbasi, A. and Rasmussen, K. (2012) 'Trend and efficiency analysis of co-authorship network', Scientometrics, Vol. 90, No. 2, pp. 687-699.

Uddin, S., Hossain, L. and Rasmussen, K. (2013) 'Network effects on scientific collaborations', PloS one, Vol. 8, No. 2, e57546.

Van Raan, A.F.J. (2004) 'Internationalization in science in the prism of bibliometric indicators', in Moed, H.F. Glänzel, W. and Schmoch, U. (Eds.): Handbook of Quantitative Science and Technology Research, Kluwer Academic Publishers, Dordrecht, pp. 19-50.

Wang, X., Xu, S., Wang, Z., Peng, L. and Wang, C. (2013) 'International scientific collaboration of China: Collaborating countries, institutions and individuals', Scientometrics, Vol. 95, No. 3, pp. 885-894.

Wang, Y., Wu, Y., Pan, Y.T., Ma, Z. and Rousseau, R. (2005) 'Scientific collaboration in China as reflected in co-authorship', Scientometrics, Vol. 62, No. 2, pp. 183-198.

World Health Organization (2005) 'China: health, poverty and economic development, Office of the WHO Representative in China, and Social Development Department of the China State Council Development Research Centre, Beijing.

Zitt, M. and Bassecoulard, E. (2004) 'Measuring Science', in Moed, H.F., Glänzel, W. and Schmoch, U. (Eds.): Handbook of Quantitative Science and Technology Research, Kluwer Academic Publishers, Dordrecht, pp. 407-436.

Zhou, P. and Bornmann L. (2015) 'An overview of academic publishing and collaboration between China and Germany', Scientometrics, Vol. 102, pp. 1781-1793.

Zhou, P. and Glänzel W. (2010) 'In-depth analysis on China's international cooperation in science', Scientometrics, Vol. 82, pp. 597-612.

Zhou, P. and Leydesdorff, L. (2006) 'The emergence of China as a leading nation in science', Research policy, Vol. 35, No. 1, pp. 83-104. 


\section{Appendix}

Figure A1 Co-publications network between China and UK ${ }^{9}$

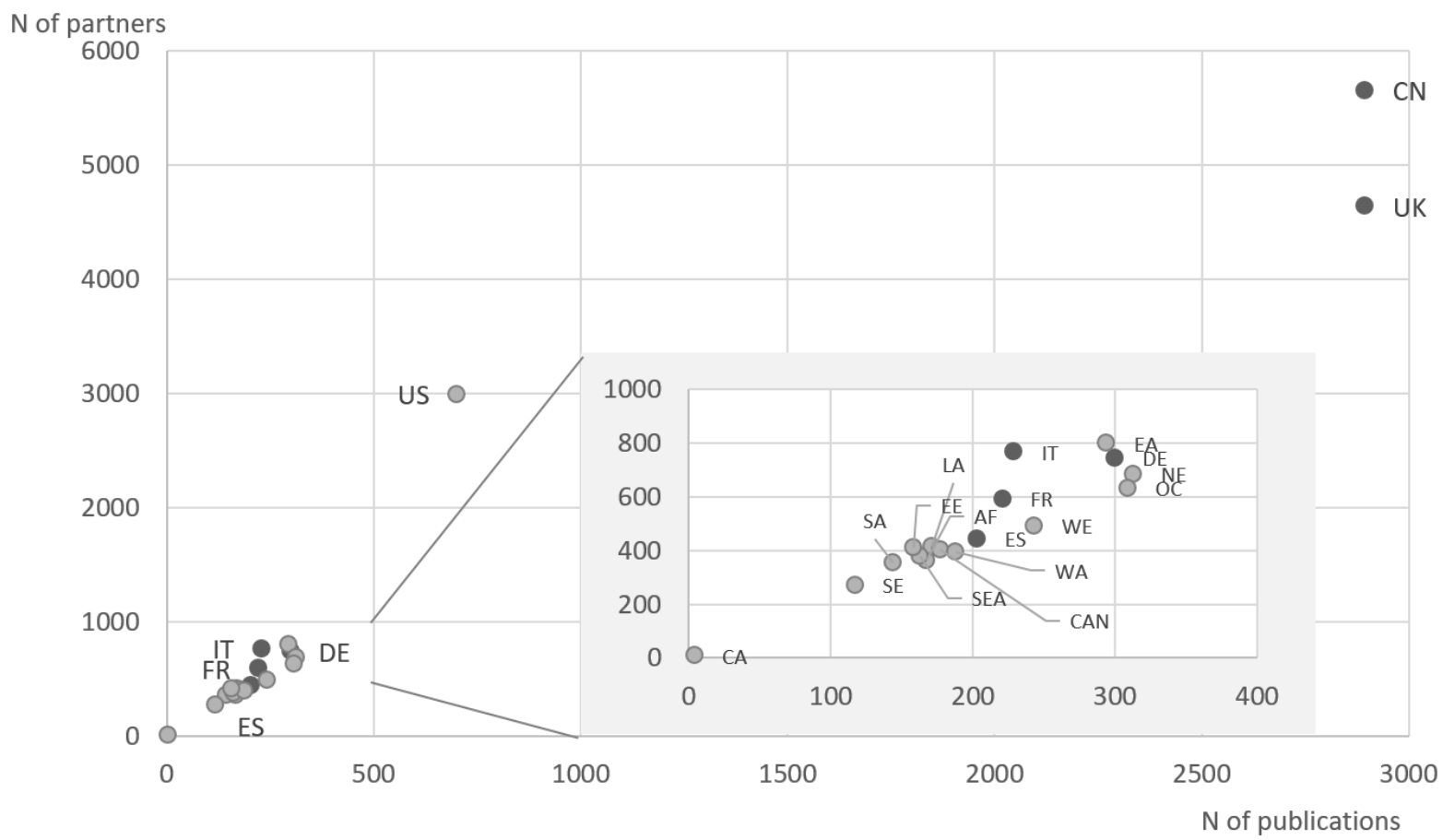

Source: authors' elaboration on SCOPUS data.

Figure A2 Co-publication network between China and Germany ${ }^{8}$

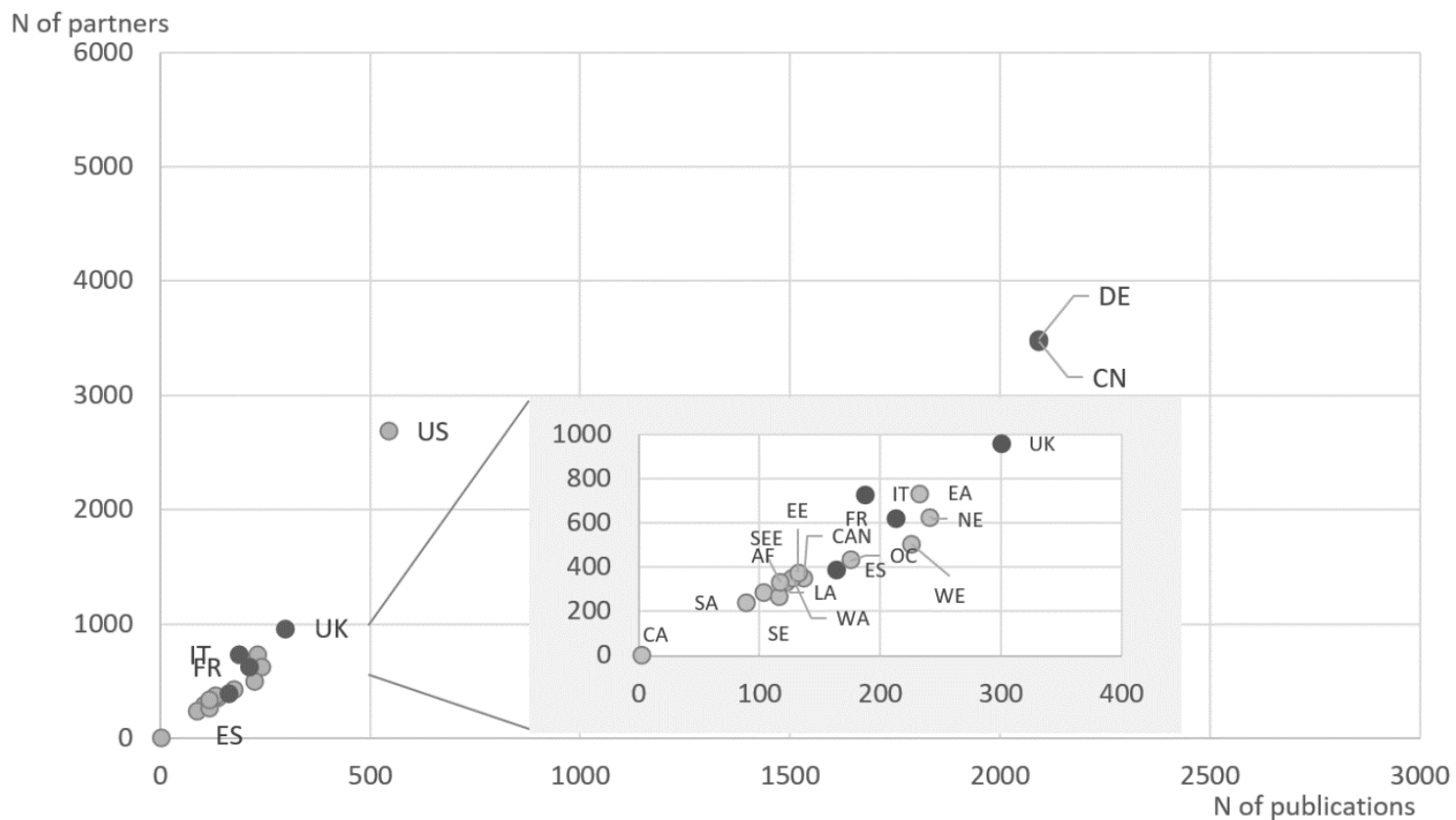

Source: authors' elaboration on SCOPUS data.

\footnotetext{
${ }^{9}$ Legend for countries and regions: AF - Africa, CA - Central Asia, CAN - Canada, CN - China, DE - Germany, EA - Eastern Asia (China excluded), EE - Eastern Europe, ES - Spain, FR - France, IT - Italy, LA - Latin America, NE - Northern Europe (United Kingdom excluded), OC - Oceania, SA - Southern Asia, SEA - South-eastern Asia, SE - Southern Europe (Italy and Spain excluded), UK - United Kingdom, US - USA, WA - Western Asia, WE - Western Europe (France and Germany excluded).
} 
Figure A3 Co-publication network between China and France ${ }^{8}$

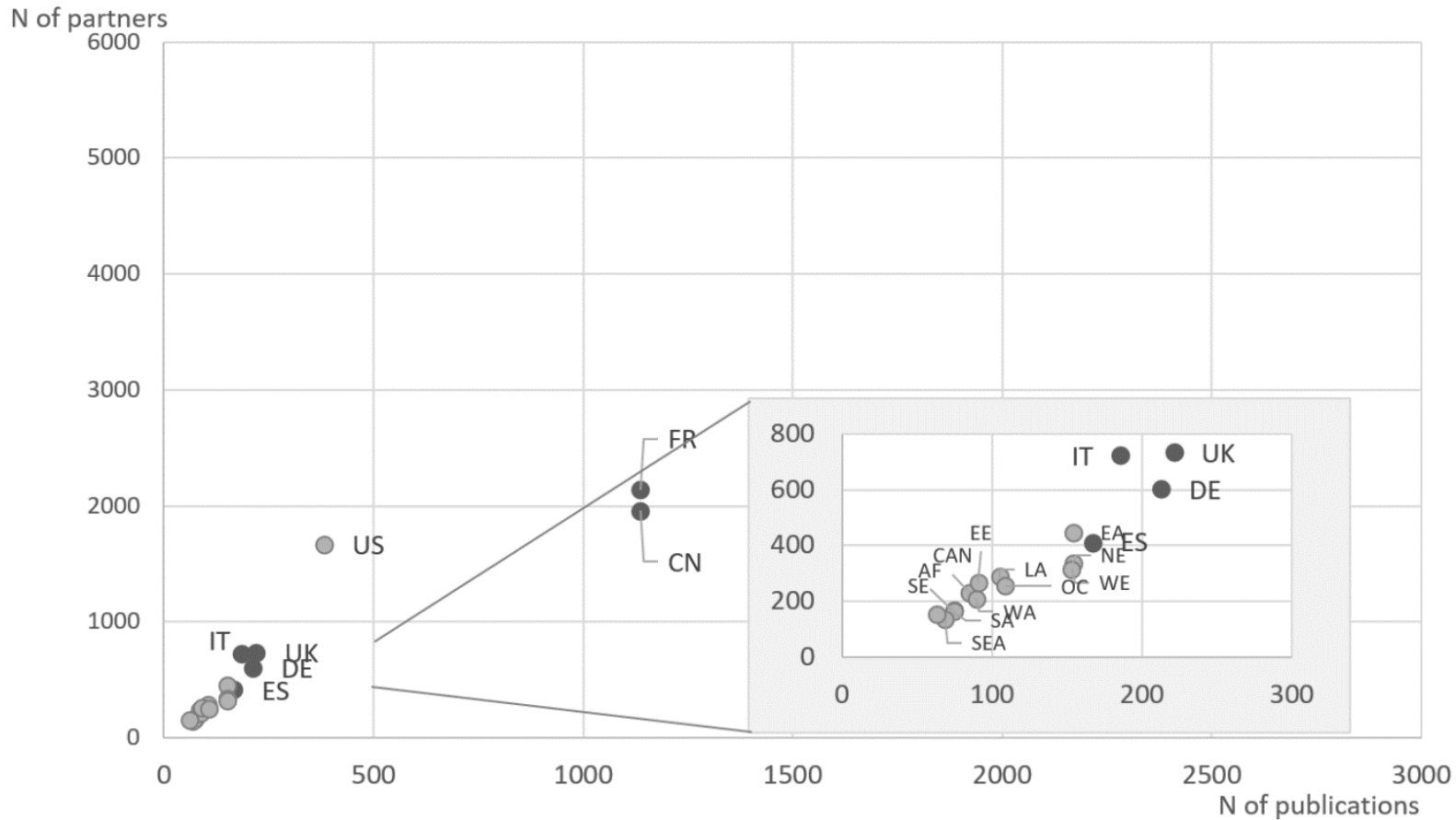

Source: authors' elaboration on SCOPUS data.

Figure A4 Co-publication network between China and Italy ${ }^{8}$ $\mathrm{N}$ of partners

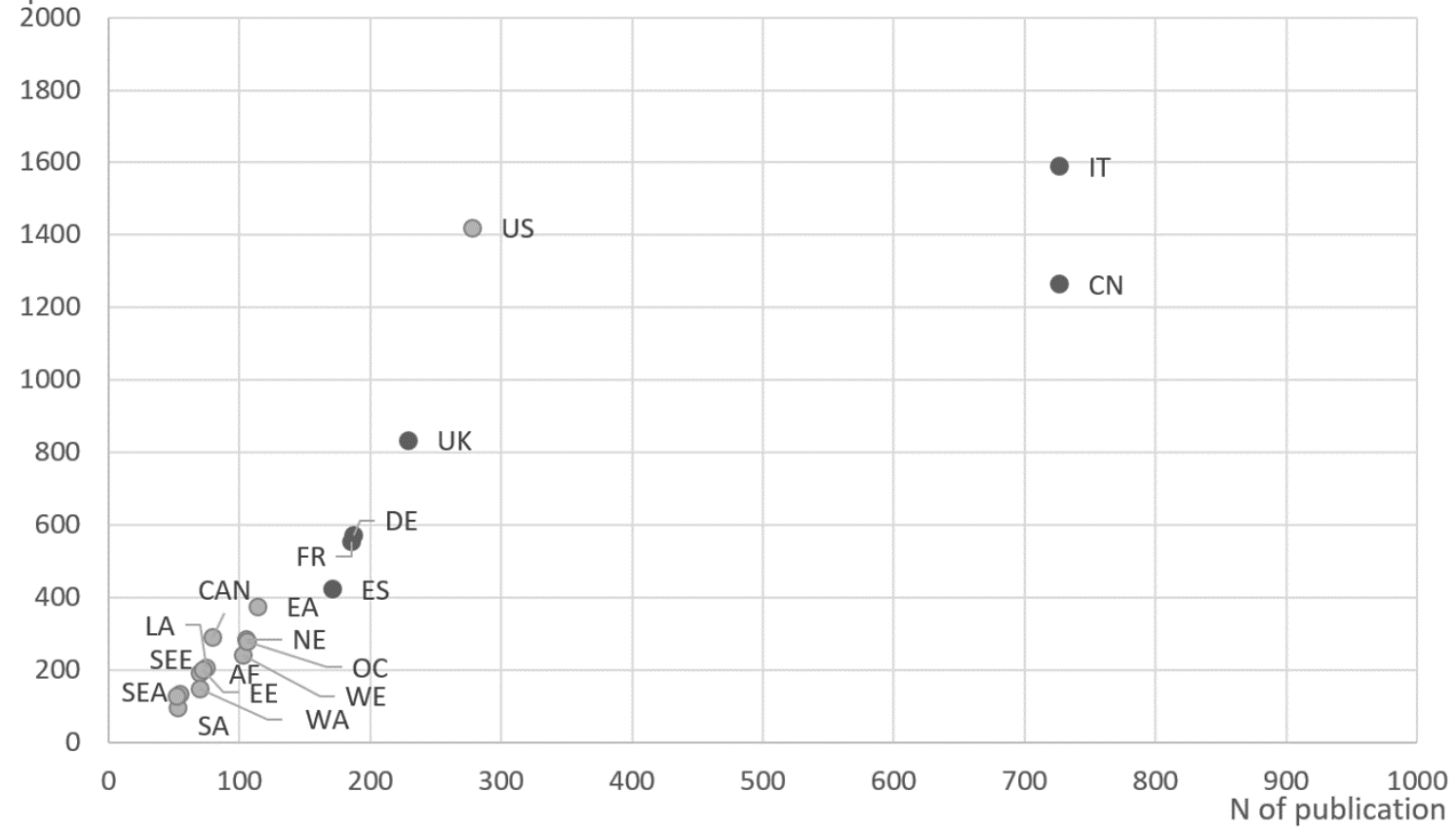

Source: authors' elaboration on SCOPUS data. 
Figure A5 - Co-publication network between China and Spain ${ }^{8}$ $\mathrm{N}$ of partners

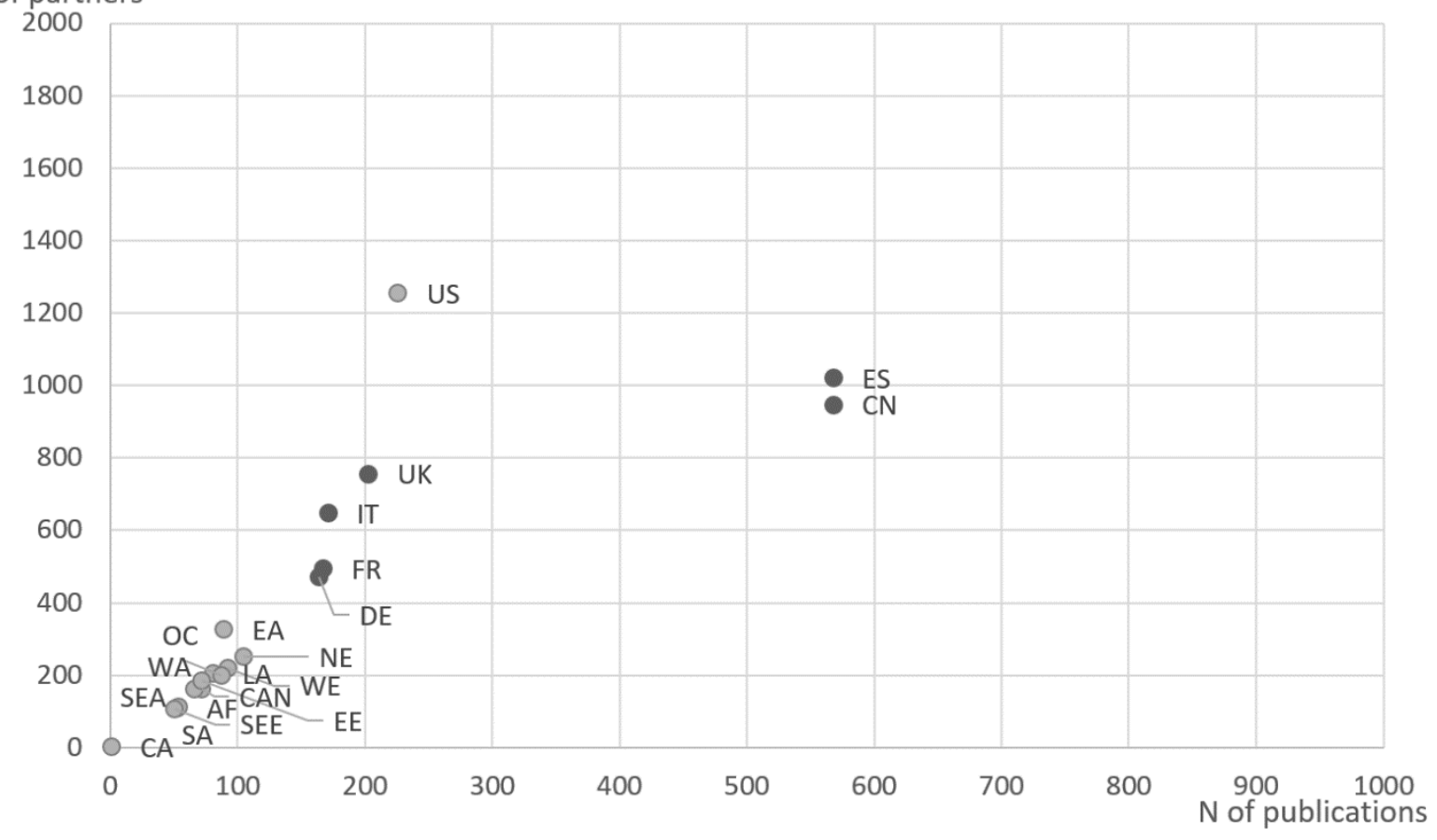

Source: authors' elaboration on SCOPUS data. 


\section{TABLES}

Table 1 Ranking of worldwide contributors, various years.

\begin{tabular}{|c|c|c|c|c|c|c|}
\hline & 1990 & 1995 & 2000 & 2005 & 2010 & 2014 \\
\hline 1 & United States & United States & United States & United States & United States & United States \\
\hline 2 & UK & Japan & Japan & China & China & China \\
\hline 3 & Japan & UK & UK & UK & UK & UK \\
\hline 4 & Germany & Germany & Germany & Germany & Germany & Germany \\
\hline 5 & France & France & France & Japan & Japan & Japan \\
\hline 6 & Canada & Canada & China & France & France & India \\
\hline 7 & Italy & Italy & Italy & Canada & Canada & France \\
\hline 8 & Netherlands & China & Canada & Italy & Italy & Italy \\
\hline 9 & Australia & Netherlands & Russia & Spain & India & Canada \\
\hline 10 & India & Russia & Spain & Australia & Spain & Australia \\
\hline .. & China (13) & & & & & \\
\hline
\end{tabular}

Source: authors' elaboration on SCOPUS data.

Table 2 Salton's measures: co-publishing intensity between China and the five selected countries, years 2000 and 2014

\begin{tabular}{lcccc}
\hline \hline & \multicolumn{2}{c}{2000} & \multicolumn{2}{c}{2014} \\
& Total & Health & Total & Health \\
\hline UK & 0.012 & 0.009 & 0.029 & 0.024 \\
Germany & 0.011 & 0.007 & 0.019 & 0.018 \\
France & 0.006 & 0.004 & 0.016 & 0.012 \\
Italy & 0.005 & 0.003 & 0.009 & 0.008 \\
Spain & 0.003 & 0.002 & 0.008 & 0.007 \\
\hline Source: authors'
\end{tabular}

Table 3 Institutions from the 5 selected countries involved in collaboration agreements in the health sector with the NSFC, year 2016

\begin{tabular}{lll}
\hline Country & & Institution(s) \\
\hline United Kingdom & - & The Royal Society (RS); \\
& - & Biotechnology and Biological Science Research Council (BBSRC); \\
& - & The Medical Research Council of United Kingdom of Great Britain and \\
& & Northern Ireland (MRC); \\
& - & The Royal Society of Edinburgh (RSE); \\
& - & The Economic and Social Research Council of United Kingdom of Great \\
& & Britain and Northern Ireland; \\
Germany & - & Science \& technology facilities Council \\
France & - & Ceutsche Forschungsgemeinschaft (DFG) \\
Italy & - & Agence Nationale de la Recherche (ANR) \\
Spain & - & Consiglio Nazionale delle Ricerche (CNR) \\
\hline
\end{tabular}

Source: NSFC website. 
Table 4 Overview of the co-publishing activity with China for the five selected countries, year 2014.

\begin{tabular}{lcccc}
\hline \hline & $\begin{array}{c}\text { Number of co- } \\
\text { publications } \\
\text { with China }\end{array}$ & $\begin{array}{c}\text { Number of } \\
\text { bilateral co- } \\
\text { publications }\end{array}$ & $\begin{array}{c}\text { Avg number of } \\
\text { partners per } \\
\text { publication }\end{array}$ & $\begin{array}{c}\text { Avg number of } \\
\text { regions/countries } \\
\text { per publication }\end{array}$ \\
\hline United Kingdom & 2894 & 1509 & 8.04 & 3.48 \\
Germany & 2093 & 1002 & 8.82 & 3.65 \\
France & 1136 & 463 & 12.17 & 4.44 \\
Italy & 726 & 161 & 17.83 & 5.86 \\
Spain & 568 & 88 & 19.83 & 6.35 \\
Source: authors' elaboration on SCOPUS data. & & &
\end{tabular}

Table 5 Distribution of affiliations across types of institutions

\begin{tabular}{lrrrrrr}
\hline & $\begin{array}{r}\text { Association } \\
\text { /Foundation }\end{array}$ & Company & Hospital & Pub. Inst. & University \\
hospital & University \\
\hline United Kingdom & 5.15 & 4.40 & 7.65 & 2.78 & 6.92 & 73.09 \\
Germany & 9.36 & 5.84 & 3.58 & 10.99 & 11.71 & 58.53 \\
France & 6.64 & 2.90 & 10.71 & 25.07 & 11.83 & 42.84 \\
Italy & 4.91 & 3.72 & 21.41 & 13.48 & 7.62 & 48.87 \\
Spain & 14.02 & 1.67 & 10.69 & 16.57 & 17.84 & 39.22 \\
China & 0.51 & 2.45 & 7.84 & 5.22 & 17.13 & 66.86 \\
\hline So
\end{tabular}

Source: authors' elaboration on SCOPUS data. 


\section{FIGURES}

Figure 1 Weight of China's publications on tot. SCOPUS publications (\%)

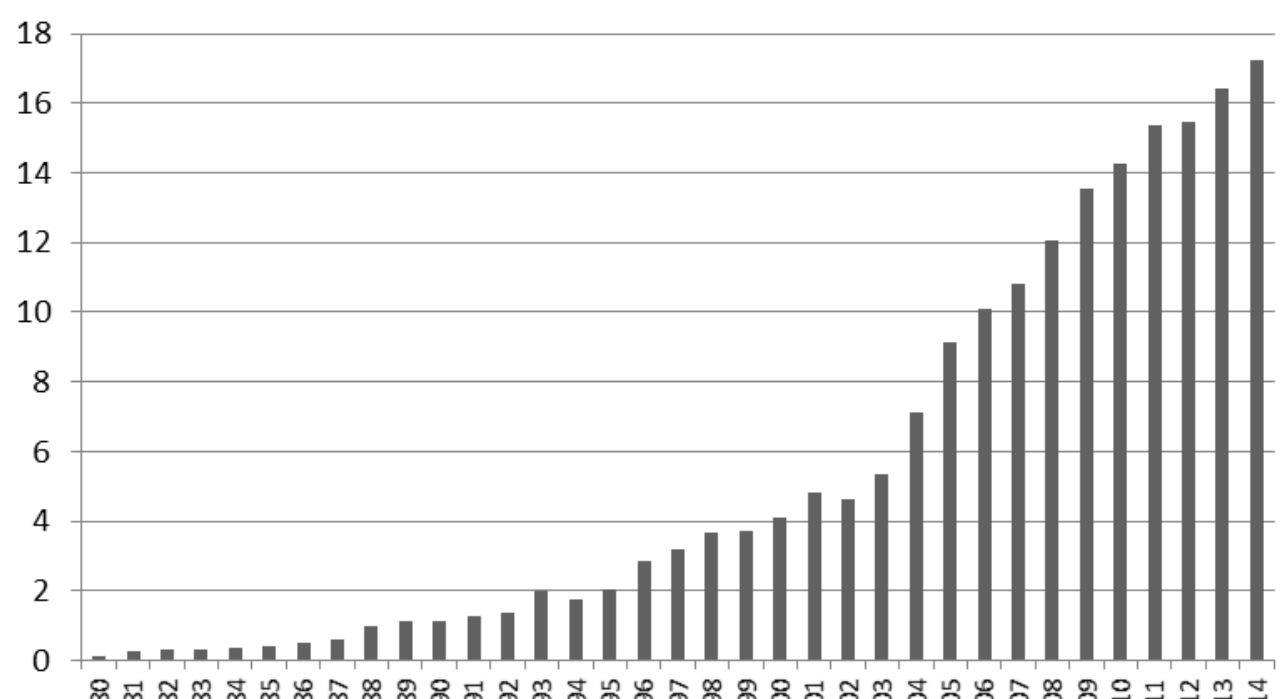

ஜ

Source: authors' elaboration on SCOPUS data.

Figure 2 Chinese publications and their weight of world publications in health-related subjects

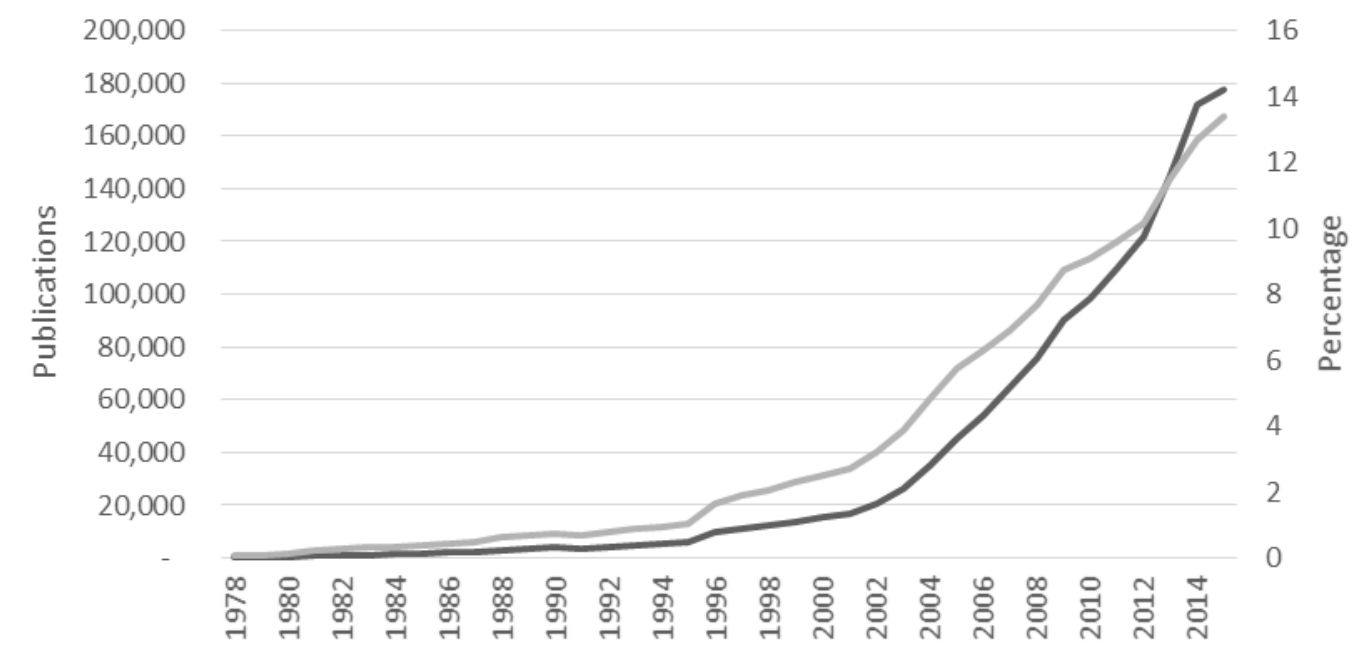

- N Chinese publications in the field _ as a \% of world publications in the field

Source: authors' elaboration on SCOPUS data. Notes: \% of world publication on right axis. 
Figure 3 Activity index: specialization in the field of health subjects. Time series (China) and 2014 (first 10 contributors)

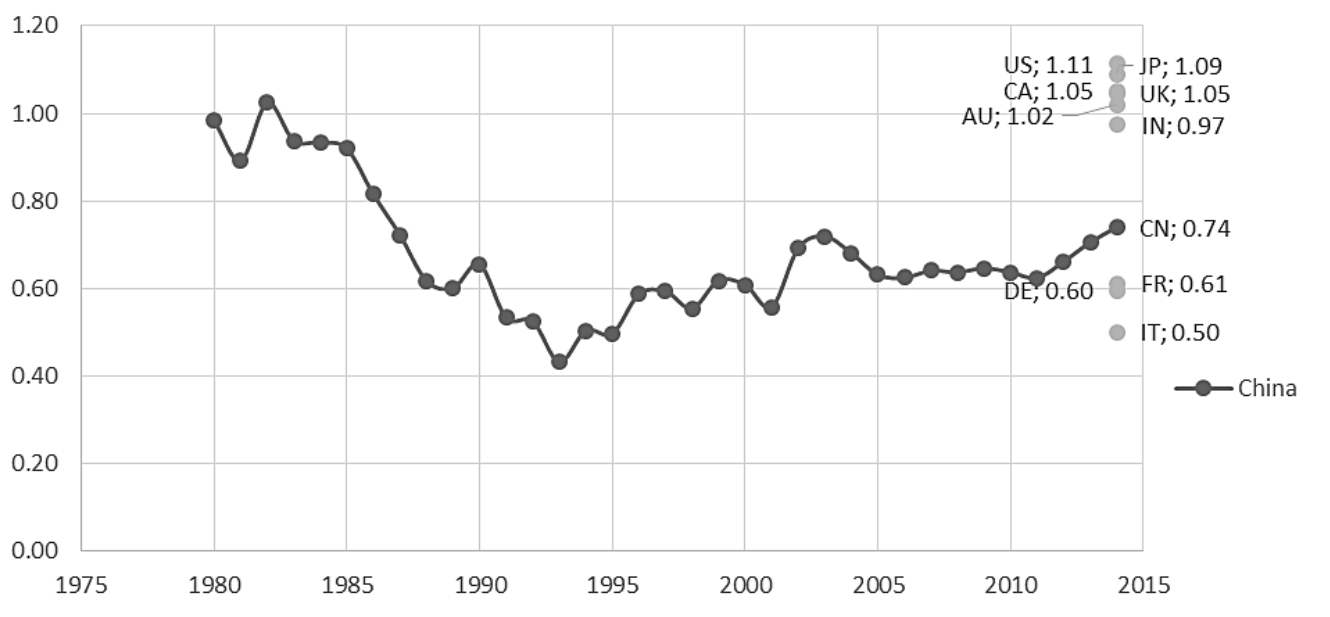

Source: authors' elaboration on SCOPUS data.

Figure 4 Chinese internationally co-authored publications in the field: number of papers and number of countries

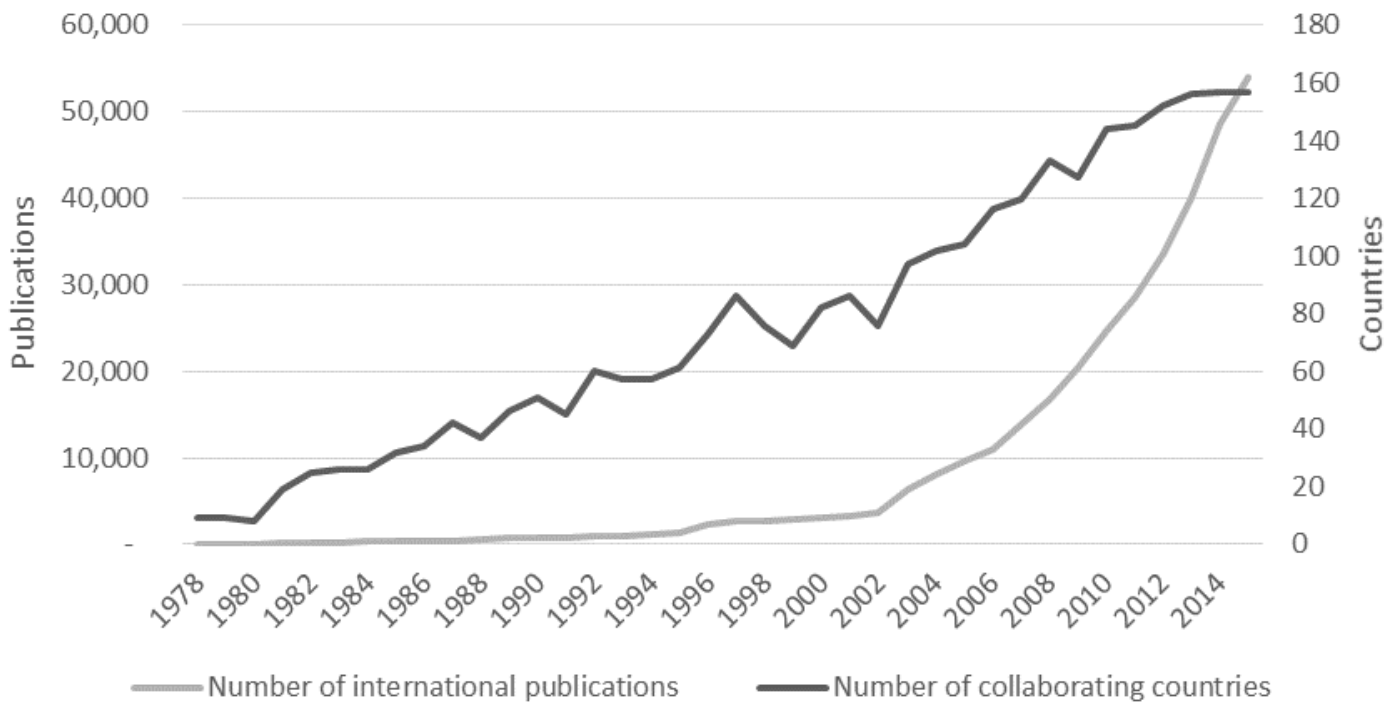

Source: authors' elaboration on SCOPUS data. Notes: number of countries on right axis.

Figure 5 The position of 5 EU selected countries in collaborations in health with China 


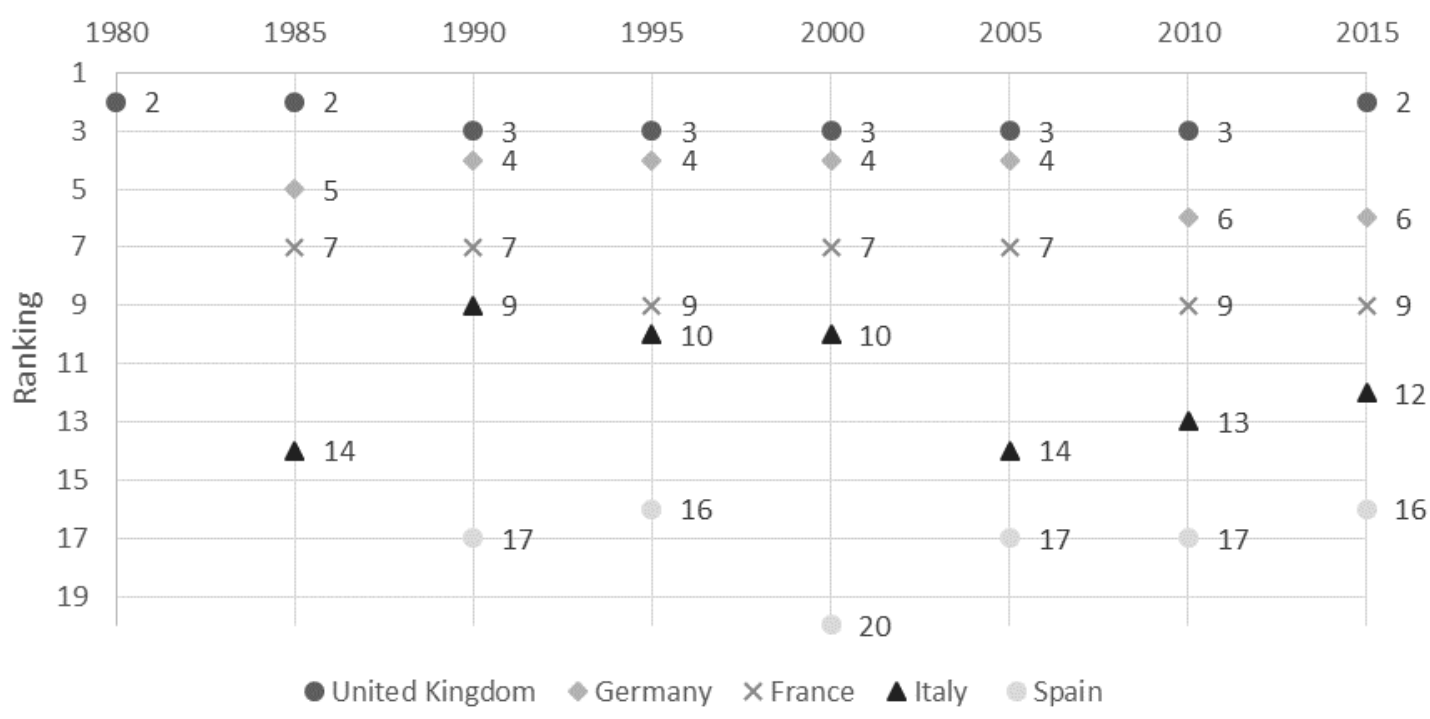

Source: authors' elaboration on SCOPUS data.

Figure 6 The complexity index $C_{i}$ for the co-publications between China and the five European countries

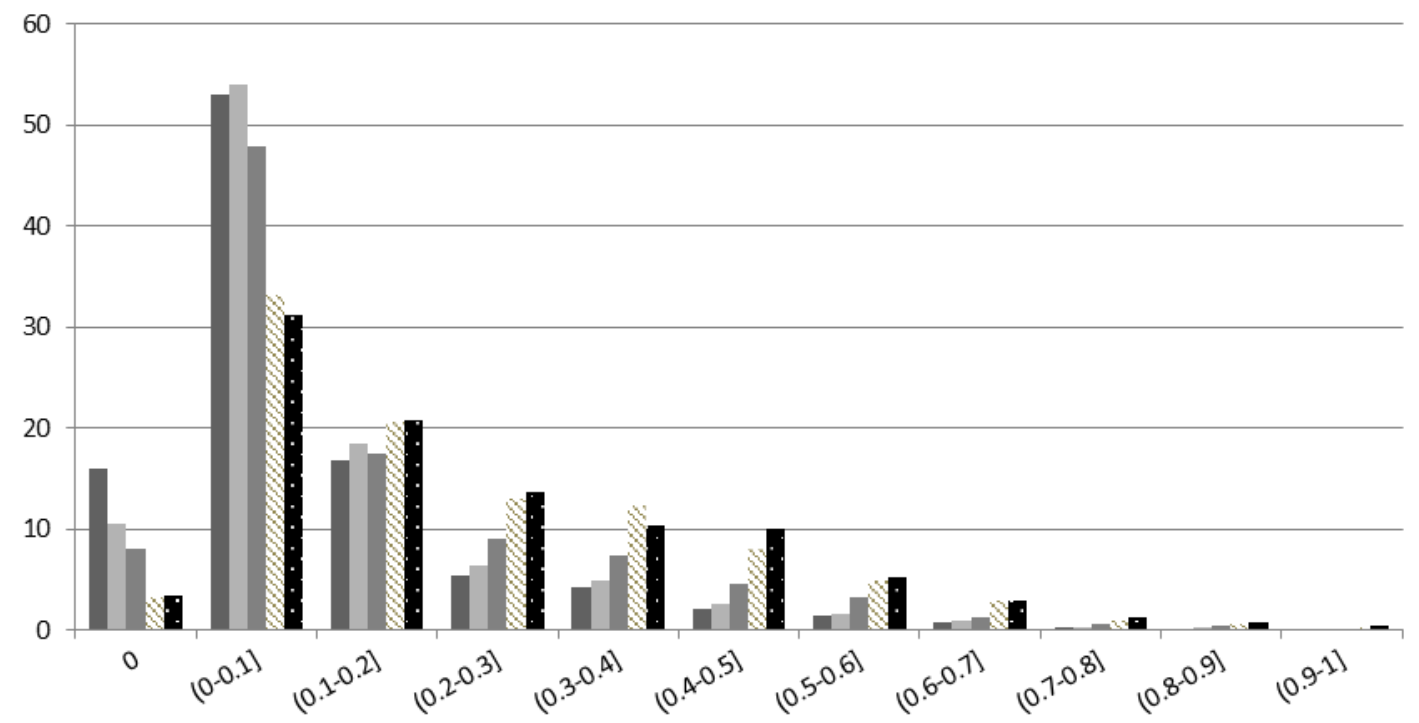

$$
\text { United Kingdom Germany } \square \text { France \&Italy Spain }
$$

Source: authors' elaboration on SCOPUS data. 